\title{
Mesenchymal stem cells are recruited to striated muscle by NFAT/IL-4-mediated cell fusion
}

\author{
Manja Schulze, ${ }^{1,2,3}$ Fikru Belema-Bedada, ${ }^{1,2,3}$ Antje Technau, ${ }^{2}$ and Thomas Braun ${ }^{1,2,4}$ \\ ${ }^{1}$ Max-Planck-Institute for Heart and Lung Research, 61231 Bad Nauheim, Germany; ${ }^{2}$ Institute for Physiological Chemistry, \\ Martin-Luther-University-Halle-Wittenberg, 06097 Halle, Germany
}

\begin{abstract}
Mesenchymal stem cells (MSCs) or mesenchymal adult stem cells (MASCs) that are present in the stroma of several organs have been proposed to contribute to the regeneration of different tissues including liver, blood, heart, and skeletal muscle. Yet, it remains unclear whether MSCs can be programmed to differentiate cell-autonomously into fully functional cells or whether they are recruited by surrounding cells via fusion and thereby acquire specialized cellular functions. Here, we demonstrate that Wnt signaling molecules activate the expression of distinct sets of genes characteristic for cardiac and skeletal muscle cells in MASCs. However, such cells lack morphological criteria characteristic for functional muscle cells and do not show contractile activity. In contrast, MASCs fuse efficiently with native myotubes in an IL-4-dependent manner to form functional hybrid myotubes. Injection of genetically labeled MSCs into wild-type mouse blastocysts revealed a contribution to skeletal but not cardiac muscle development. Disruption of IL-4 and NFATc2/c3 reduced or prevented a contribution of adult stem cells to the development of Il-4 and NFATc2/c3 mutant embryos, further emphasizing the apparent inability of adult stem cells to differentiate fully into striated muscle in a cell-autonomous manner.
\end{abstract}

[Keywords: Mesenchymal stem cells; heart; muscle development; regeneration]

Supplemental material is available at http://www.genesdev.org.

Received February 3, 2005; revised version accepted June 6, 2005.

Stem cells are undifferentiated cells capable of self-renewal by asymmetric division, which can give rise to different types of specialized cells by successive divisions. Until recently the mainstream view focused on local, renewable stem cells, which are located within the respective organ to contribute to replacement of organspecific cells. It was generally assumed that these cells are determined and already committed toward differentiation into a specific lineage. The stability of cellular determination, however, was questioned by transplantation experiments, which suggested that determined cells can be manipulated to acquire various fates when exposed to different cellular environments (Ferrari et al. 1998; Gussoni et al. 1999; Jackson et al. 1999).

For several cell types, the environmental signals that induce cellular fate decisions during normal embryonic development have been well defined. Embryonic skeletal myogenesis, for example, is induced by an interplay of

\footnotetext{
${ }^{3}$ These authors contributed equally to this work.

${ }^{4}$ Corresponding author.

E-MAIL thomas.braun@kerckhoff.mpg.de; FAX 011-49-6032-705-211. Article and publication are at http://www.genesdev.org/cgi/doi/10.1101/ gad.339305.
}

numerous growth factors including members of the Wnt family, which are released from the neural tube and the surface ectoderm, and responsive mesodermal cells that react upon induction by expression of cell-type-specific myogenic factors (Neuhaus and Braun 2002). Cardiomyocytes develop from the anterior part of the lateral plate mesoderm known as cardiac crescent, which acquires a cardiac fate in response to signals from the adjacent endoderm (Olson and Schneider 2003). In this case, Wnt proteins appear to inhibit cardiogenesis (Tzahor and Lassar 2001), although Wnt11, which seems to act via a noncanonical PKC, JNK-dependent pathway, stimulates cardiomyocyte development in various assays (Eisenberg and Eisenberg 1999; Pandur et al. 2002).

In adult organisms, inductive myogenic signals might affect only local stem cells, which are probably already committed to the muscle lineage, or, alternatively, other stem cells, which circulate or are normally located at remote locations (Ferrari et al. 1998; Bittner et al. 1999; De Angelis et al. 1999). Circulating stem cells have recently been proposed to contribute to repair processes and homeostasis of several organs including skeletal muscle (Polesskaya et al. 2003) and the heart (Orlic et al. 
2001). In addition, it has been suggested that cells that copurify with mesenchymal stem cells (termed multipotent adult progenitor cells, or MAPCs) are able to differentiate, at the single-cell level, into cells with visceral mesoderm, neuroectoderm, and endoderm characteristics (Jiang et al. 2002). Since differentiated cells derived from MAPCs have not been subjected to a comprehensive functional characterization, it is difficult to judge whether differentiation of these cells was mimicked by activation of dominant regulatory circuits without gaining a functionally significant phenotype or whether a full functional conversion was achieved. Similarly, technical approaches based exclusively on immune fluorescence staining to track cell fate and to monitor cell differentiation in vivo might create a bias that leads to false-positive results. Interestingly, two recent studies that used transgenic markers instead of immunofluorescence to identify transplanted cells failed to detect differentiation of lin $^{-}$c-kit ${ }^{+}$stem cells into cardiomyocytes (Balsam et al. 2004; Murry et al. 2004).

Several groups have shown that stem cells spontaneously generated hybrids with differentiated cells in vitro, indicating that transdetermination consequent to cell fusion might underlie many observations otherwise attributed to an intrinsic plasticity of tissue stem cells (Ying et al. 2002). Muscle cells inherently rely on cell fusion to generate functional tissue and might therefore be particularly prone to recruit naive cells into cellular syncytiae. So far, it is generally assumed that only determined muscle progenitor cells fuse to each other or to pre-existing myotubes in a highly regulated manner. The molecular cues that direct this process are not completely understood, although several cell surface, extracellular, and intracellular molecules that facilitate fusion have been defined recently (Dworak and Sink 2002; Taylor 2002; Horsley and Pavlath 2004). Of specific importance is the calcineurin/NFAT pathway, which directs myoblast fusion in part by controlling IL-4 gene activity (Horsley et al. 2003). Muscle cells, which are defective of NFATc2 or NFATc3, are characterized by morphological changes, in particular, thin myotubes (NFATc2) or a reduced number of myofibers per muscle (NFATc3), leading to a decreased muscle size (Horsley et al. 2001; Kegley et al. 2001).

In this study, we investigated the ability of distinct subsets of mesenchymal stem cells to respond to inductive cues by activation of distinct sets of genes characteristic for cardiac and skeletal muscle cells. Although mesenchymal stem cells did not form functional muscle cells on their own, they fused efficiently with native myotubes in an IL-4-dependent manner. Similar observations were made in vivo, where genetically labeled mesenchymal stem cells contributed to skeletal but not cardiac muscle development after injection into wildtype mouse blastocysts. Interestingly, this contribution was diminished or even abrogated when IL-4 and NFATc2/c3 embryos were used as hosts, indicating that the input of mesenchymal stem cells (MSCs) is probably due to NFAT-controlled fusion to host skeletal myotubes.

\section{Results}

Wnt molecules and FGF-2/BMP-2 activate expression of skeletal and cardiac muscle cell genes in MSCs

The birth of skeletal muscle cells during development depends on various inductive signals including $\mathrm{SHH}$ and Wnt molecules. Cardiac cell identity, on the other hand, is controlled by members of the TGF $\beta$ superfamily of growth factors, by FGFs, and by Wnt molecules (Olson and Schneider 2003). While BMPs and FGFs appear to act as cardiac inducers, the role of Wnts seems less straightforward since both induction and suppression have been reported (Pandur et al. 2002; Zaffran and Frasch 2002).

We reasoned that embryonic signals might also stimulate muscle cell differentiation in adult mesenchymal stem cells, which have been proposed to be multipotent in respect to their differentiation capability. Two distinct multipotent mesenchymal cell populations (termed mBM-MASC1 and mBM-MASC2) were isolated from mouse bone marrow and expanded in DMEM-LG supplemented with $10 \%(\mathrm{v} / \mathrm{v})$ FCS without additional growth-promoting cytokines. After a series of passages, mBM-MASCs became homogeneous and were devoid of nonadherent hematopoietic cells. FACS analysis revealed differences in the expression level of Sca-1 and CD34 between both populations, while the expression of other surface molecules such as c-Kit, CD45, Ter119 or glycophorinA, Flk-1, SSEA-1, CD133(Profilin), CD13, and MHCI or $\mathrm{H}-2 \mathrm{D}^{\mathrm{d}}$ was virtually indistinguishable $(\mathrm{F}$. Belema-Bedada, A. Techmau, H. Ebelt, M. Schulze, and T. Braun, in prep.). Without additional treatment, these isolates essentially did not express heart or skeletal muscle markers as indicated by immunohistochemistry and RT-PCR with the exception of a low-level expression of single marker genes such as Pax3 (data not shown). However, when mBM-MASC1 and mBMMASC2 were cocultured together with Wnt11 expressing murine NIH3T3 or human HEK293T cells, multiple morphological and biochemical changes were noted. Most importantly, mBM-MASCs expressed the skeletalmuscle-specific myogenic determination factors Myf-5, MyoD, Myogenin, and MRF4 as revealed by RT-PCR and by immunohistochemical staining for Myogenin (Fig. 1A; data not shown). In addition, we found expression of sarcomeric skeletal muscle proteins $\mathrm{MyHC}$, TnI, and TnT, although we never observed multinucleated fused myotubes or sarcomeric cross-striations, which are indicative of full terminal differentiation. Quantitative assessment revealed that $9.8 \% \pm 6 \%(n=7)$ of all cells in the culture expressed sarcomeric skeletal muscle proteins (data not shown).

Heart muscle cells are characterized by a distinct set of specific genes, which are inactive in skeletal muscle cells. To investigate the induction of a cardiac muscle cell phenotype, we examined the expression of several cardiac-specific genes by RT-PCR and immunohistochemistry after cocultivation of mBM-MASC1 with Wnt11-expressing cells. We detected a robust expression of Nkx-2.5, GATA-4, $\beta-M y H C$, BNP, Hand2, TEF1, and 


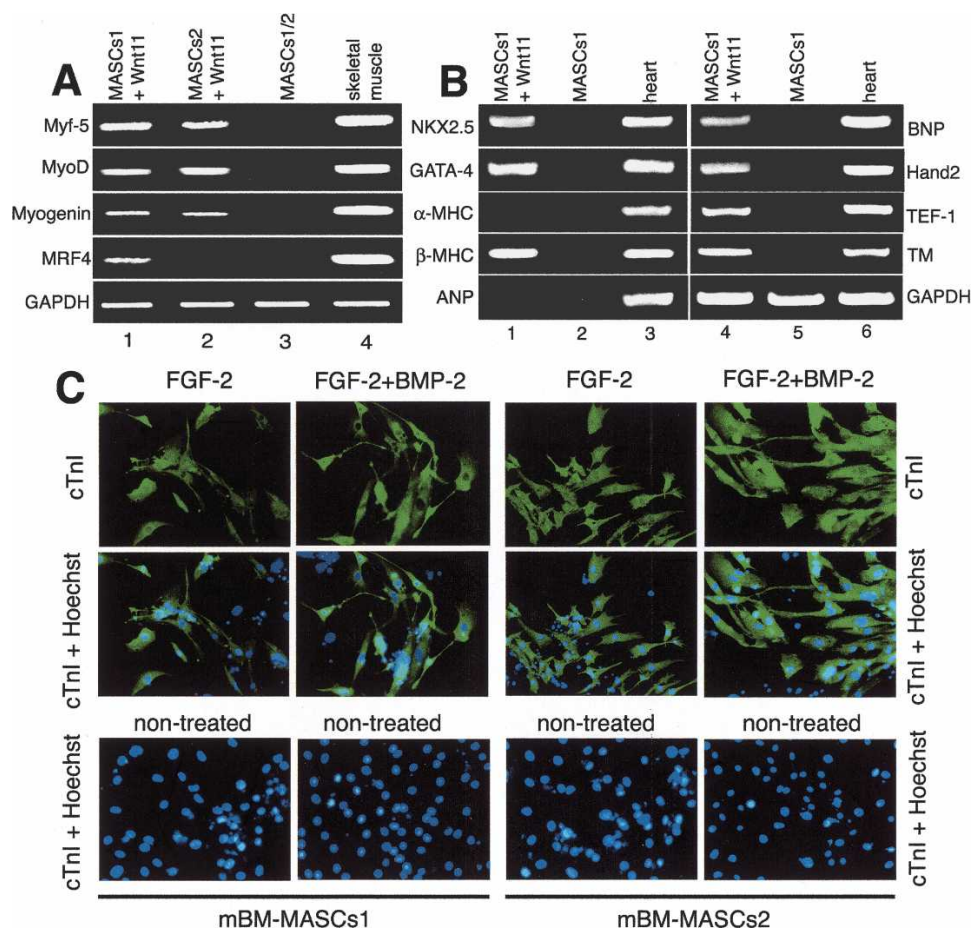

Figure 1. Activation of skeletal and heart-muscle-specific genes in mBM-MASCs. $(A, B)$ RT-PCR analysis of RNA isolated from mBM-MASCs1 or mBM-MASCs2 cocultured for $7 \mathrm{~d}$ with Wnt11-expressing cells. (A) Expression of skeletal muscle markers Myf5, MyoD, Myogenin, and MRF-4 in Wnt11-treated mBM-MASCs1 (lane 1), Wnt11-treated mBM-MASCs2 (lane 2), untreated mBM-MASCs1/2 (lane 3), and in skeletal muscle (lane 4). (B) Expression of heart muscle markers Nkx2.5, GATA4, $\alpha$-MHC, $\beta$-MHC ANP, BNP, Hand2, TEF-1, and TM (tropomyosin) in Wnt11-treated mBMMASCs1 (lanes 1,4), untreated mBM-MASCs1 (lanes 2,5), and in the heart (lanes 3,6). GAPDH expression was used as a loading control in $A$ and $B$. Treatment with Wnt11 leads to activation of a subset of skeletal or heart-muscle-specific markers. $(C)$ Immunofluorescent staining of the cardiac marker cTnI in FGF-2 and FGF2/BMP-2 treated mBM-MASCs1 and mBM-MASCs2. cTnI expression was undetectable in untreated mBMMASCs1 and mBM-MASCs2. Nuclei were visualized using DAPI. The photographs in $C$ were taken with a 100× magnification. tropomyosin by RT-PCR (Fig. 1B) and of the sarcomeric proteins cTnT, cTnI, and $\mathrm{MyHC}$ by immunohistochemistry (data not shown). However, we were unable to identify a reproducible expression of other typical cardiomyocyte genes such as $\alpha-\mathrm{MyHC}$ and ANP. Similarly, addition of FGF-2, BMP-2, and combinations of both evoked an expression of cTnI (Fig. 1C) and a limited set of cardiac marker genes such as Nkx-2.5 and GATA-4 in mBM-MASC1 and mBM-MASC2 (data not shown). Depending on the individual experiment, between $8 \%$ and $15 \%(n=7)$ of mesenchymal adult stem cells (MASCs) stained positive for either Nkx-2.5 or GATA-4. Yet, close inspection of cTnI-positive cells revealed a highly aberrant cellular morphology (i.e., no crossstriations, flat shape, irregular size) that was not characteristic of cardiomyocytes (Fig. 1C). In addition, we never spotted cells with an organized contractile apparatus or cells that underwent spontaneous contractions, which are hallmarks of functional cardiac muscle cells. We did not observe an initiation of the cardiac and skeletal muscle program in mBM-MASCs when cells were treated with conditioned medium from Wnt-expressing cells (data not shown), indicating that either direct cell-to-cell contacts are necessary or that the concentration of biologically active Wnt molecules in the medium did not suffice to stimulate expression of myogenic markers.

Comparable results were obtained using mesenchymal stem cells that were derived from various other tissues including heart and skeletal muscle. Although these cells displayed minor differences in the expression of stem cell marker molecules, they showed virtually the same capabilities as bone-marrow-derived cells analyzed in this study (F. Belema-Bedada, in prep.).
Fusion to myotubes or cardiomyocytes is the predominant mechanism of $\mathrm{mBM}$-MASCs to achieve full myogenic differentiation

Several groups have claimed to obtain contracting heart muscle cells and functional skeletal muscle cells in vitro after cocultivation of stem cells from various sources with bona fide muscle cells or after injection into regenerating host tissues in vivo. These reports are in apparent conflict to our observations, which indicated only a partial activation of the heart and skeletal muscle programs. It seems possible, however, that cocultivation of differentiated cells with stem cells might give rise to a mixture of cells displaying a partially differentiated phenotype as well as at least some semifunctional hybrid cells, which are derived from a fusion of uncommitted stem cells with fully differentiated cells.

In fact, our cocultures of skeletal muscle cells or cardiomyocytes with MASCs labeled either with DiI or by virus-mediated delivery of the GFP gene also yielded labeled spontaneously contracting cardiomyocytes and myotubes that were apparently derived from labeled MASCs (data not shown). Such cells stained positive for both the cell tracking dye (GFP or DiI) and for musclecell-specific sarcomeric proteins (MyHC and cTnI in the case of cardiomyocytes) (Fig. 2; Supplementary Fig. 1), raising the possibility that either differentiation of MASCs or fusion with C2C12 myoblasts had occurred. The appearance of double-labeled skeletal muscle cells was not a rare event. In selected experiments up to $5.9 \% \pm 1.3 \%(n=6)$ of all labeled MASCs stained positive with MyHC myotubes, although this ratio varied considerably (two- to threefold) between individual tests. 


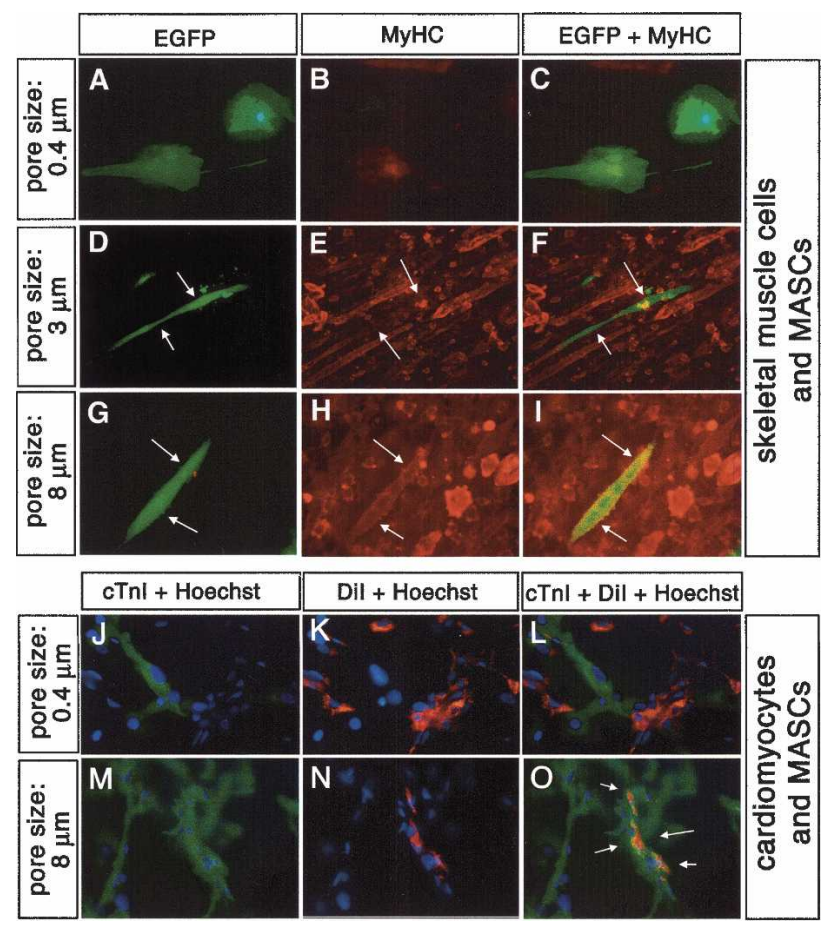

Figure 2. Recruitment of MASCs into functional skeletal and cardiac muscle cells requires cell fusion. Ad-EGFP $(A-I)$, DiIlabeled MASCs $(J-O)$, C2C12 myogenic cells $(A-I)$, and primary cardiomyocytes $(J-O)$ were plated on opposite sides of polycarbonate filters of different pore sizes as indicated. After 5-6 d of culture, cells were stained with antibodies against myosin heavy chain (MyHC) $(B, C, E, F, H, I)$ and $\mathrm{cTnI}(J, M, L, O)$. (D-I,M$O)$ Labeled MASCs that stained positive both for EGFP or DiI and $\mathrm{MyHC}$ or cTnI were found only when filters with a relatively larger pore size were used and are indicated by arrows. The photographs in $A-L$ were taken with a $100 \times$ magnification.

Interestingly, many more DiI- or GFP-labeled myotubes than cardiomyocytes were obtained in these experiments. Only $1.1 \% \pm 0.5 \%(n=5)$ of all labeled MASCs were found to express cTnI after cocultivation with cardiomyocytes. To distinguish whether GFP- or DiI-labeled myotubes and cardiomyocytes were exclusively derived from MASCs, thus reflecting cell-autonomous differentiation events ("bona fide differentiation"), or resulted from a fusion of GFP- or DiI-labeled MASCs with cardiomyocytes and myotubes, we repeated the coculture experiments. However, this time we placed the "inducing" differentiated cardiomyocytes or myotubes on one side of a membrane and the labeled MASCs on the other. For this purpose, we used membranes with pore sizes of $0.4,3$, and $8 \mu \mathrm{m}$, which either allow passage of cells $(8 \mu \mathrm{m})$ or prevent transmigration $(<3 \mu \mathrm{m})$. As shown in Figure 2, no DiI-labeled cardiomyocytes or GFP-labeled myotubes were present in cultures in which membranes $<3 \mu \mathrm{m}$ were used, whereas marked myotubes (Fig. 2I) and cardiomyocytes (Fig. 2L) were readily found in cultures with membranes of 8 - $\mu$ m pore size (myotubes: $1.9 \% \pm 1.1 \%, n=4$; cardiomyocytes: $0.5 \% \pm 0.3 \%$ ). In experiments with membranes of 3 - $\mu$ m pore size, the for- mation of hybrid myotubes was not completely abrogated (Fig. 2F), although significantly fewer double-labeled cells were observed $(0.6 \% \pm 0.3 \%, n=4)$. These data strongly suggest that the generation of functional heart and skeletal muscle cells from MASCs was not based on inductive cues but involved fusion with differentiated muscle cells.

\section{Recruitment of nonmyogenic cells to myotubes might result in an initial compartmentalization of hybrid myotubes}

To further prove that recruitment of MASCs into functional muscle cells relies on cell fusion, we next turned to a heterologous system using human bone-marrow-derived mesenchymal adult stem cells (hBM-MASCs) and differentiated rodent cells to allow easy identification of the origin of individual cellular nuclei (Blau et al. 1985). In this system, human nuclei appear paler than mouse nuclei and contain less punctuated, brightly fluorescent nucleoli after staining with the fluorescent dye DAPI (Fig. 3). Similar to the results obtained with cocultures of mouse cells, we detected a strong GFP fluorescence in some myotubes (Fig. 3A, inset) that stained positive for MyHC (Fig. 3A,C). In addition, such myotubes occasionally showed spontaneous contractions like their unlabeled counterparts. A close inspection of DAPI-stained cultures revealed that all myotubes that displayed GFP fluorescence contained a combination of mouse and human nuclei as indicated by their characteristic morphological features (Fig. 3B). We did not find a single GFP myotube that contained solely human nuclei, which strongly suggests that at least one nucleus from a bona fide muscle cell is required to reprogram hBM-MASCs.

We then decided to have a closer look at the process of reprogramming by staining hybrid myotubes with antibodies against Myogenin, a muscle-specific nuclear protein, and prolyl 4-hydroxylase, a cytoplasmic antigen, which is not present in myotubes but in hBM-MASCs. As shown in Figure 3E and F, hybrid myotubes displayed an unequal distribution of these antigens in hybrid myotubes at an early time point of cocultivation. Nuclei that contained the myogenic regulatory factor Myogenin were found only in one-half of the myotube, whereas nuclei in the contralateral part of the cell were devoid of Myogenin (Fig. 3F). A mirror-like pattern applied for the cytoplasmic antigen prolyl 4-hydroxylase, which was found only close to nuclei that lacked Myogenin. Between both areas, we noticed a border zone characterized by a reduced concentration of prolyl 4-hydroxylase (Fig. 3F). Upon further cocultivation of myotubes and hBMMASCs and hybrid myotubes, the initial compartmentalization vanished and a homogeneous staining occurred. Taken together, these experiments document an ongoing reprogramming of hBM-MASCs and an acquisition of the myogenic phenotype. Importantly, the process of reprogramming of hBM-MASCs into functional myotubes seemed to be initiated by the fusion to predetermined muscle cells and not by cell-autonomous bona fide differentiation events. 

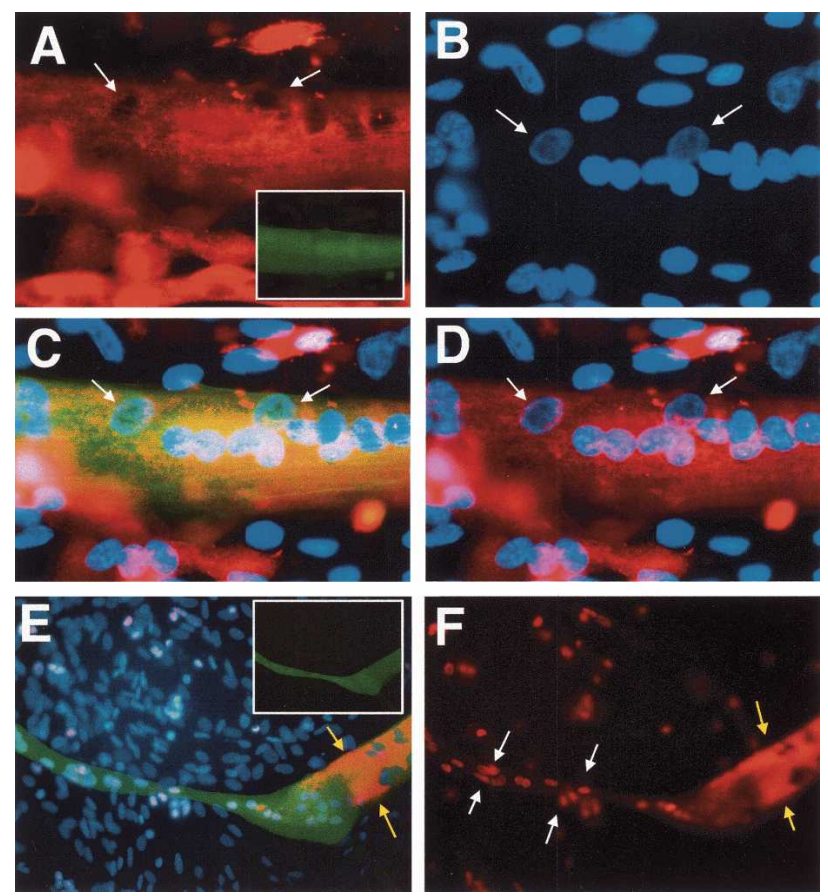

Figure 3. Human mesenchymal stem cells are recruited by mouse myogenic cells to form interspecies hybrid myotubes. $(A-D)$ Human Ad-GFP-labeled MASCs and C2C12 myogenic cells were cocultivated, stained for MyHC expression, and treated with DAPI to reveal the origin of the nuclei. Human nuclei (indicated by arrows in $A-D$ ) are larger and paler than their mouse counterparts, which fluorescence more brightly. (A) MyHC staining of a hybrid myotube. The inset in $A$ shows the GFP fluorescence of the same myotube. (B) DAPI staining. (C) Overlay of the MyHC staining (red fluorescence), DAPI staining (blue), and GFP fluorescence (green). (D) Overlay of the MyHC staining (red fluorescence), DAPI staining (blue). $(E, F)$ Partially reprogrammed hybrid myotube resulting from the coculture of Ad-GFP-labeled MASCs and C2C12 myogenic cells. (E) Overlay of GFP-staining (green), DAPI staining (blue), and prolyl 4-hydroxylase (red), an antigen not detected in myogenic cells. The inset in $E$ shows the green channel alone. Note that all Ad-GFP-labeled MASCs in the view field have fused to the myotube. $(F)$ Staining of the hybrid myotube with antibodies against prolyl 4-hydroxylase (cytoplasmic antigen, present in the right half of the hybrid myotube) and Myogenin (nuclear antigen, present in the nuclei of the left half of the hybrid myotube). Note the zonal expression of MASCs and myogenic antigens in the hybrid myotube. The photographs in $A-D$ were taken with a $1000 \times$ magnification and those in $E$ and $F$ were taken with a $200 \times$ magnification.

\section{Nonmyogenic MASCs fuse to myocytes in an $I L-4$-dependent fashion}

During normal skeletal muscle development, fusion of myoblasts to each other and to pre-existing myotubes is controlled by several different cell surface, extracellular, and intracellular molecules. Recently it has been shown that IL-4, which itself is transcriptionally controlled by NFATc2 and NFATc3, plays a major role in this process (Horsley et al. 2003; Pavlath and Horsley 2003). We wanted to explore whether IL-4 does contribute to the fusion of MASCs with myogenic cells. Therefore, we added IL-4 at $5 \mathrm{ng} / \mathrm{mL}$ to cocultures of GFP-labeled human or mouse MASCs and C2C12 myogenic cells (Fig. 4C) and scored the number of labeled myotubes that also stained positive for MyHC. As shown in Figure 4A, addition of IL-4 increased the number of "recruited" myotubes up to $300 \%$, resulting in $17.7 \% \pm 4.2 \%(n=6)$ of all labeled MASCs ending up in myotubes. In a complementary experiment, we added neutralizing antibodies directed against the IL-4-receptor (IL-4R $\alpha$ ) or IL-4 to the cultures without supplementation of exogenous IL-4. Importantly, antibodies against IL-4 reduced the number of "recruited" myotubes by $\sim 50 \%$ | $=2.95 \% \pm 1.5 \%$ of all labeled MASCs), while inhibition of the IL-4 receptor (IL-4R $\alpha$ ) using rather low antibody concentrations, decreased the number of GFP-labeled myotubes by $\sim 75 \%$

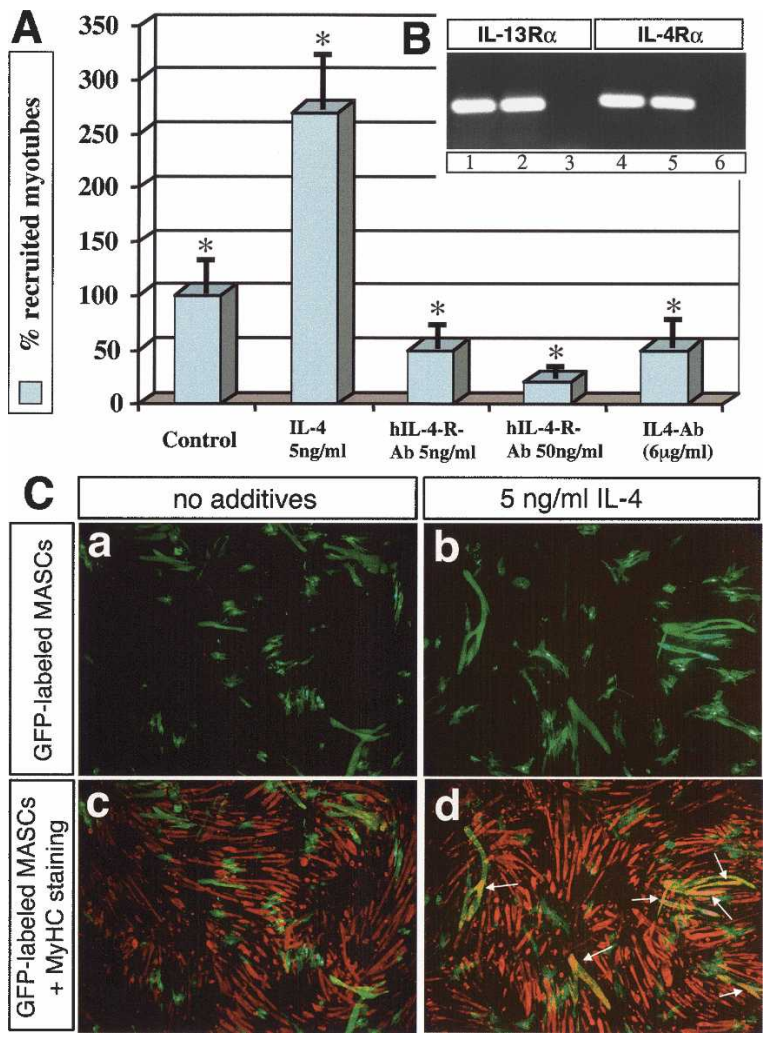

Figure 4. Mesenchymal stem cells fuse in an IL-4-dependent manner with myogenic cells. $(A, C)$ GFP-labeled MASCs and $\mathrm{C} 2 \mathrm{C} 12$ myogenic cells were cocultivated in the absence or presence of IL-4 and of antibodies against IL-4 or the IL-4 receptor and stained consecutively for MyHC. $(C$, panel $d)$ Double-labeled myotubes appear orange-yellow and are indicated by arrows. Bars in $A$ indicate the number of cells that were positive for both GFP and MyHC expression. Error bars in $A$ show the standard deviation. $\left(^{*}\right) P<0.05$. Note that addition of IL-4 stimulated recruitment of MASCs to a myogenic fate by fusion, while addition of antibodies against IL-4 and its receptor inhibited recruitment. (B) RT-PCR analysis of the expression of the IL-13R $\alpha 1$ (lanes 1-3) and the IL-4 $\alpha 1$ receptors (lane 4-6) in hBMMASCs (lanes 1,3), human fibroblasts (lanes 2,5), and in negative controls (lanes 3,6$)$. The photographs in $C$ were taken with a $50 \times$ magnification. 
( $=1.35 \% \pm 0.75 \%$ of all labeled MASCs $)$, indicating that the IL-4 pathway plays a major role in the in vitro conversion of mesenchymal stem cells into muscle cells. MASCs express both subunits of the type II IL-4R, which is composed of the IL-4R $\alpha$ and the IL-13R $\alpha 1$ chains (Fig. 4B). Unlike the type I IL-4-R, the type II IL-4R is widely found in nonhematopoetic tissues and binds both IL-4 and IL-13 (Chatila 2004).

The broader ligand-binding abilities of type II IL-4R might, at least partially, explain why we did not achieve a complete inhibition of cell fusion, in particular, when we used antibodies against IL-4. On the other hand, it is likely that IL-4 is not the sole mediator of cell fusion (see below). Furthermore, it might be technically difficult to achieve a complete neutralization of IL-4 and its receptors in culture, indicated also by the lower efficiency of inhibition using antibodies against IL-4 compared to its receptor.

Injection of labeled mesenchymal stem cells into blastocysts results in a contribution of genetically labeled MASCs to skeletal but not cardiac muscle

To further delineate the extent of the contribution of mBM-MASCs to muscle cell development, we introduced MASCs derived from MLC1/3-LacZ transgenic mice (Kelly et al. 1995) into early 3.5-d-old mouse C57/ BL6 blastocysts. MLC1/3-LacZ mice express the LacZ gene specifically in heart and skeletal muscle cells (Fig. $6 \mathrm{~A}, \mathrm{~F}, \mathrm{~K}$, below) and thus allow an unequivocal identification of cells that have activated the myogenic program. Recipient blastocysts received between 10 and 20 MASCs per embryo and developed at a normal rate, showing no obvious malformations, indicating that the injection of MASCs did not perturb differentiation of inner mass cells. Chimerism was assessed in different parts of the embryo (head, trunk, or heart) or in pools of tissues by PCR-based detection of the bacterial LacZ reporter gene, which is specifically present only in the genome of injected MASCs. The LacZ transgene was detected in $>90 \%$ of all injected and surviving embryos at embryonic day 10.5 (E10.5) and E13.5, although the signal strength varied considerably between individual embryos, indicating a different degree of chimerism. We did not find significant differences in the degree of chimerism between different parts of the embryo (Fig. 5).

To investigate the potential of MASCs to contribute to heart and skeletal muscle development, we stained chimeric embryos between E10.5 and E13.5 for MLC1/3LacZ activity. As shown in Figure 6B, G, and L, we found LacZ-positive cells only in differentiated myotomal cells of E10.5 embryos, which give rise to the skeletal musculature, but not in the heart (out of 408 chimeric animals analyzed), although the MLC1/3-LacZ transgenic strain also expressed lacZ in cardiomyocytes during embryonic development (Fig. 6A,K). It should be pointed out that the number of embryos expressing MLC1/3LacZ was rather low. Only $<5 \%$ of chimeric embryos contained LacZ-positive cells, and a larger contribution of LacZ-positive cells was found in $<1 \%$ of chimeric em-

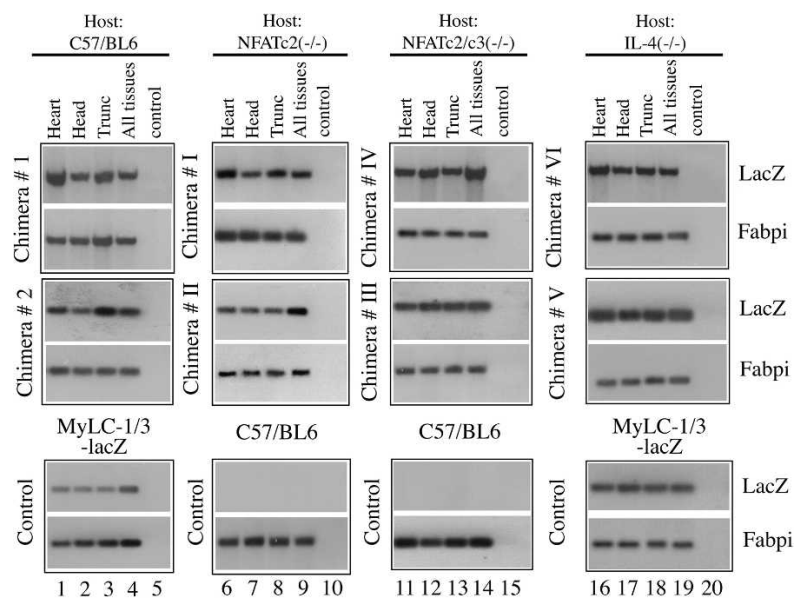

Figure 5. Robust engraftment of MASC mBM-MASCs into different host embryos of the mouse. Detection of engraftment of genetically labeled mBM-MASCs into host blastocysts of C57/ BL6, NFACTc2 $2^{-/-}$, NFACTc $2 / \mathrm{c}^{-/-}$, and IL-4 $4^{-/-}$mice by PCR. LacZ transgenic and nonchimeric C57/BL6 mice served as positive and negative controls, respectively. LacZ-specific primers were used to detect the presence of mBM-MASC-derived cells in different organs of host embryos. Primers specific for the Fabpi gene (intestinal fatty acid-binding protein) were used as an internal control.

bryos. At present it is hard to distinguish whether this discrepancy is solely due to a comparatively low ability of MASCs to contribute to muscle cell development or reflects a higher sensitivity of the PCR-based approach to detect injected MASCs. It is clear, however, that only a minor proportion of injected MASCs activated the MLC1/3-LacZ myogenic marker.

Closer inspection of MLC1/3-LacZ-positive cells in chimeric embryos revealed that the $\beta$-galactosidase marker, which contains a nuclear localization signal, was present only in a subset of nuclei of MLC1/3-LacZpositive cells (Fig. 7A), leaving some nuclei unstained. No myotube was found in chimeric embryos that was solely derived from MLC1/3-LacZ MASCs and thus lacked unstained nuclei. In contrast, in transgenic MLC1/3-LacZ donor mice, all nuclei of myotomal myotubes stained positive for $\beta$-galactosidase (Fig. 7B). Similar results were obtained after explantation and cultivation of myotomal cells in vitro using an antibody to detect the $\beta$-galactosidase protein (Supplementary Fig. 2). This finding strongly reminded us of the unequal distribution of MASCs and the Myogenin antigen in hybrid myotubes in vitro at early time points of cocultivation (Fig. 3F).

Contribution of genetically labeled MASCs to myogenic development in chimeric mouse embryos depends on NFAT signaling

In the previous section we demonstrated that MASCs are most probably recruited by cell fusion into skeletal myotubes during embryonic development. Furthermore, we showed that MASCs fuse efficiently with native myo- 


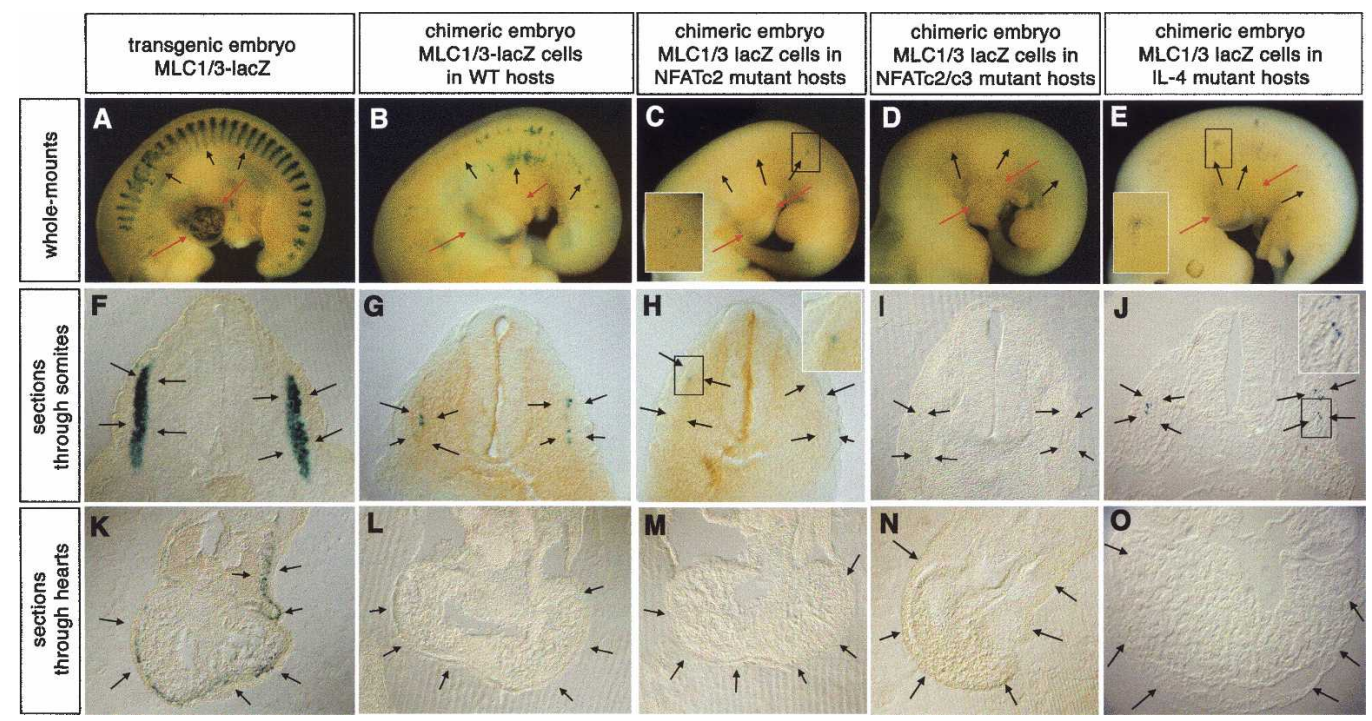

Figure 6. The contribution of genetically labeled MASCs to skeletal but not heart development depends on NFAT signaling. LacZ staining of transgenic MyLC1/3-LacZ transgenic $(A, E, I)$ and chimeric $(B-E, G-I, L-O)$ mice at E10.5. C57/BL6 (B,G,L), NFATc2 ${ }^{-/-}$ $(C, H, M)$, NFATc2 $/ \mathrm{c}^{-/-}(C, I, N)$, and IL-4 $4^{-/-}(E, I, O)$ embryos served as hosts. $(A-E)$ Whole-mount preparations. $(F-J)$ Sections through the neural tube and adjacent somites. $(K-O)$ Sections through the heart. $(A)$ Expression of the MyLC1/3-LacZ transgene in the heart (red arrows) and in somatic myotome (black arrows) is clearly visible in transgenic embryos. ( $F, J)$ In C57/BL6 hosts only an expression in somites is present. Virtually no expression of the MyLC1/3-LacZ transgene is seen in NFATc2 ${ }^{-/-}(C)$ and NFATc2/c3 ${ }^{-/-}(D)$ host embryos both in the somites $(H, I)$ and in the heart $(M, N)$, while the contribution to muscle development seems reduced in IL-4 ${ }^{-/-}(F, J)$ hosts, indicating a requirement for NFAT-mediated recruitment of MASCs to the myogenic lineage. The photographs $F-O$ were taken using Nomarski optics with a $100 \times$ magnification.

tubes in an IL-4-dependent manner in vitro to form functional hybrid myotubes. We next wanted to explore whether IL-4 and/or NFATc2/c3-signaling is also required in vivo for the recruitment of genetically labeled MASCs into myotubes.

For this purpose, we used mouse blastocysts obtained from IL-4 (Kuhn et al. 1991), NFATc2 (Schuh et al. 1998), NFATc3, and NFATc2/NFATc3 compound mutant mice (Rengarajan et al. 2002) as hosts and injected them with the same MASCs from transgenic MLC1/3-LacZ mice used in the previous experiments. NFATc2 mice are characterized by skeletal muscles with thin myotubes, while NFATc3 mice have been reported to contain a reduced number of myofibers per muscle, leading to a decreased muscle size (Horsley et al. 2001; Kegley et al. 2001). During the course of our experiments, however, we also found a large number of thin myotubes in some muscles of NFATc3 mutant mice, while IL-4 mutant mice showed a regular size of myotubes compared to control animals (Supplementary Fig. 3).

As shown in Figure 6D, I, and N, chimeric embryos that resulted from injection of NFATc2/NFATc3 compound mutant blastocysts never yielded any LacZ-positive cells $(n=112)$. Similarly, chimeras obtained after injection of NFATc2 mutant embryos in only a single case gave rise to an isolated LacZ-positive myotube (Fig. $6 \mathrm{C}, \mathrm{H}, \mathrm{M})(n=322)$. In contrast, injection of genetically labeled MASCs into IL-4 mutant hosts generated a significant number of MyLC1/2-LacZ-positive cells in the myotome of chimeric embryos (Fig. 6E,J,O) $(n=64)$, although the number of LacZ-positive cells was always lower than in wild-type (WT) hosts, suggesting an important but not decisive role of IL-4 for the recruitment of MASCs into the myogenic lineage. It should be mentioned, however, that we were unable to make a full quantitative assessment of the reduced contribution of MASCs to IL-4 and NFAT mutant hosts since the degree of chimerism inevitably varies between individual embryos.

In addition, no LacZ-positive nucleus was detected in MyHC-positive myotubes of NFATc2/c3 chimeric embryos (Fig. 7C) or after extended cultivation of somitic cells derived from chimeric embryos in vitro (Supplementary Fig. 2), strongly suggesting that MASCs contribute to skeletal muscle but not to heart development by cell fusion. Apparently, the process of cell fusion and the subsequent activation of the transgenic marker depended on the NFAT pathway and to a lesser degree on IL-4, which is a downstream target gene of NFAT signaling.

\section{Discussion}

Most if not all studies devoted to analyze differentiation of mesenchymal stem cells or transdifferentiation events are based either on single-cell analysis using immunofluorescence staining to track cell fate and to monitor cell differentiation or on global expression analysis. We have combined both approaches and also incorporated a rigorous yet sensitive in vivo test based on genetically labeled cells to avoid any bias, which might lead to falsepositive or false-negative results. Basically, we came to 


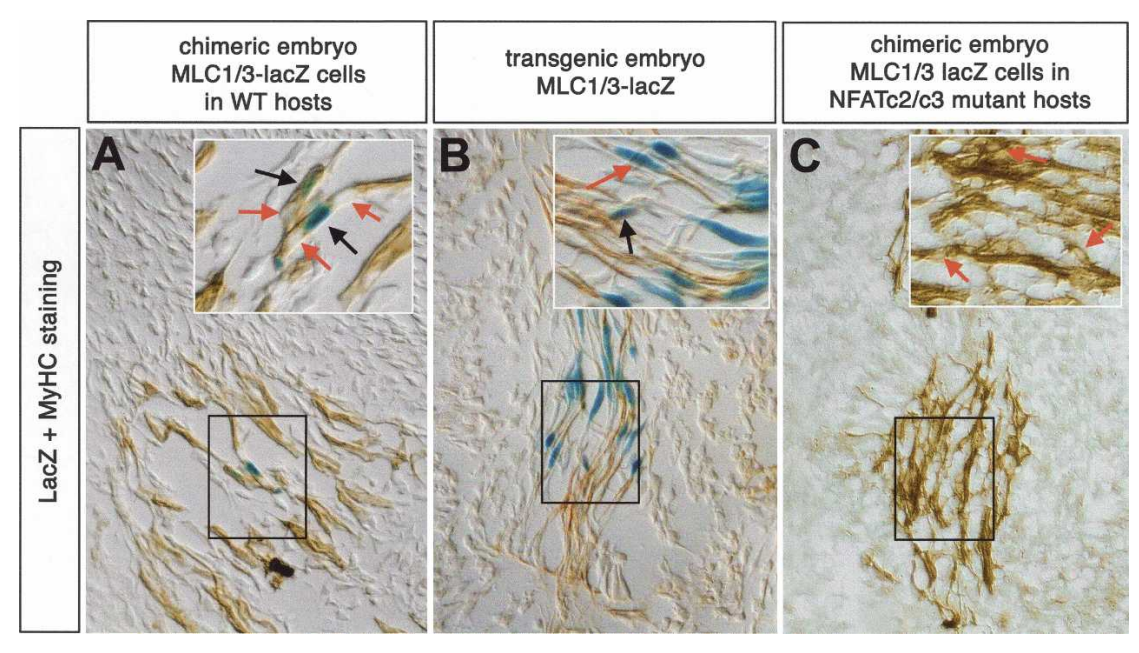

Figure 7. Genetically labeled MASCs contribute to embryonic skeletal muscle development by formation of hybrid myotubes. Combined LacZ (blue nuclear staining) and $\mathrm{MyHC}$ (brown cytoplasmic staining) staining of chimeric wild-type $(A)$ and NFATc $2 / \mathrm{c}^{-1-}$ mutant $(C)$ embryos injected with MASCs derived from transgenic MyLC1/3-LacZ mice and of noninjected transgenic MyLC1/3-LacZ mice $(B)$ at E11.5. Ten-micrometer cryosections through the trunk region are shown. LacZlabeled nuclei are only found in hybrid myotubes of wild-type hosts that also contain host-derived (not labeled) myogenic nuclei. $(C)$ No activation of the transgenic LacZ marker is detectable in NFATc2/ $\mathrm{c}^{-/-}$mutant embryos. The photographs were taken using Nomarski optics with a $200 \times$ magnification. the conclusion that certain types of MASCs can be induced to activate several cell-type-specific pathways without acquisition of a fully differentiated, functional cellular phenotype. At the same time, cocultivation of differentiated cells with MASCs will give rise to semifunctional hybrid cells, which are derived from a fusion of uncommitted stem cells with fully differentiated cells. A focus on either cell type in a mixture of fully (by fusion) and partially (by induction) differentiated cells might create the (wrong) impression that all cells undergo the same change in cellular fate. Therefore, rather different conclusions can be drawn from the same experiment depending on the type of analyses, the respective target cell, and the expectations of the researchers (Badorff et al. 2003; Murry et al. 2004).

Our claim that MASCs do not acquire a fully differentiated, functional phenotype without fusion is supported by two arguments: (1) Stem cells stimulated to acquire a myogenic phenotype expressed only a subset of genes characteristic for the respective tissues and lacked several morphological and functional properties that are typical for heart and skeletal muscle. (2) Stem cells implanted into early blastocysts did not activate the transgenic marker MLC1/3-LacZ in the heart and lacked myotubes that were exclusively derived from genetically labeled stem cells.

While the lack of certain marker molecules might be explained by the absence of some crucial factors in the growth medium or missing cell-cell and cell-matrix interaction, the failure of MASCs to activate the skeletal muscle program in vivo in a cell-autonomous way and the failure to contribute to the cardiac muscle program after transplantation into host blastocysts excludes a potential of these cells to contribute efficiently to normal organ development without further reprogramming of their cellular fate. Nevertheless, we detected a robust engraftment of MASCs into host embryos. Hence, the comparatively low contribution of MASCs to skeletal muscle development and the lack of an overt participa- tion in heart formation cannot be explained by a poor presence or absence of mesenchymal stem cells in the heart or skeletal muscle. Furthermore, disruption of NFATc2/c3 prevented a contribution of adult stem cells to the development of NFAT mutant embryos, further emphasizing the apparent inability of adult stem cells to differentiate fully into striated muscle in a cell-autonomous manner. Interestingly, the absence of a functional IL-4 gene only led to a reduction of the recruitment of MASCs to myofibers but not to a complete inhibition, indicating that other signaling molecules might substitute for the absence of IL-4 in vivo and/or that other downstream targets of NFATc2 and NFATc3 might play important roles for the recruitment of MACSs to myofibers. These findings nicely correspond to the regular size of myofibers in IL-4 mutant mice (Supplementary Fig. 3) and highlight the view that the reduction of the size of myofibers in NFAT mutant mice is only in part due to an impeded IL-4 gene activity (Horsley et al. 2003).

A major challenge for a better understanding of the biology of adult stem cells will be the identification of factors that are missing in MASCs but required to gain a fully functional, differentiated phenotype (Solloway and Harvey 2003). It is clear that the expression of such factors cannot be accomplished by environmental signals since the presence of MASC-derived cells in the heart did not suffice to complete the differentiation program. If there is no major participation of MASCs for skeletal and heart muscle formation or even for normal organ development in general, one might ask: What is the real function of mesenchymal stem cells during normal development? Are these cells remnants of past developmental decisions? Do they represent a cell population that serves a so far ill-defined purpose or are they simply the artifacts of cell isolation and expansion in vitro? Is there any significant physiological role for MASCs in embryonic development, tissue homeostasis, and repair, or do they represent an inert cell population that only passively participates in organ development? Although 
these questions cannot be answered definitively at the moment, MASCs clearly represent a species of rather plastic cells that might participate in remodeling processes of different tissues.

Since MASCs are able to respond to inductive signals by activation of cell-type-specific marker genes, it might be possible to further increase this plasticity by pushing cellular reprogramming via chromatin remodeling (Cerny and Quesenberry 2004) or by introducing critical control factors into such cells (Solloway and Harvey 2003; Lickert et al. 2004). Even if MASCs and related cells have no major physiological role for replacement of differentiated cells in diseased tissues, it cannot be excluded that they release crucial signals to activate endogenous, cell-type-specific stem cells, which might lead to an improvement of the regeneration process (Mathur and Martin 2004). In addition, some "fusiogenic" mesenchymal cells, which are not yet fully committed to myogenic differentiation, might be recruited into myotubes during development to ease a rapid expansion of the muscle lineage.

Clearly, our data challenge the view that uncommitted bone marrow or muscle-derived stem cells participate in muscle regeneration after transdifferentiating into satellite cells (Seale et al. 2000; LaBarge and Blau 2002) or that MASCs significantly contribute to the development of functional cells in undamaged recipients (Jiang et al. 2002). The initial description by Ferrari and colleagues that the same MLC1/3-LacZ transgene, which we have used in our study to monitor musclespecific gene expression, was activated in bone-marrowderived stem cells after injection into injured muscle or systemic administration might also be explained as a result of IL-4-mediated recruitment into pre-existing myotubes (Ferrari et al. 1998). The comparatively low contribution of nonmyogenic stem cells to regenerating skeletal musculature (Ferrari et al. 1998; Ferrari and Mavilio 2002; Camargo et al. 2003) and heart tissue (Fukuhara et al. 2005) also favors a view that activation of myogenic marker genes in stem cells is not due to an inherent cellular differentiation potential but results from fusion with cells of the regenerating tissue, which mimics participation of "stem cells" in the repair process (Terada et al. 2002; Wagers et al. 2002; Ying et al. 2002). In some cases, the contribution of nonmyogenic cells to regenerating musculature might even originate from inflammatory myeloid cells, which are, in the course of infrequent stochastic events, entrapped into fusogenic processes during muscle regeneration (Camargo et al. 2003).

We did not obtain any malformations, tumor formation, growth retardations, or the like in chimeric mice that might have resulted from the injection of MASCs. In addition, virtually all injected embryos implanted into the foster uterus and none of them were resorbed, a result that we see only rarely when we use embryonic stem (ES) cells to generate chimeras. Together with the comparatively high degree of chimerism, these observations indicate that MASCs are well tolerated by the host at least at early stages of development. We cannot rule out, however, that partially reprogrammed cells might give rise to physiologically aberrant cells later during life, since we have restricted our analysis mostly to prenatal stages of development. Nevertheless, we found few MLC1/3-LacZ-positive nuclei in hybrid myotubes of adult chimeras (Supplementary Fig. 4), but did not attempt a more thorough analysis due to the limited number of adult chimeric mice available. It is evident that we can only make a clear statement for the differentiation of MASCs into cardiac and skeletal muscle cells since the use of the cell-type-specific MLC-1/3-LacZ transgenic marker that excluded false-positive results in these tissues also excluded detection of a potential differentiation into other cell types.

Surprisingly, IL-4 stimulated cell fusion not only of myoblasts but also of MASCs and different preparations of primary fibroblasts (Supplementary Fig. 5), although the fusion of myoblasts to each other and to myotubes depends on a highly specialized apparatus (Dworak and Sink 2002; Horsley and Pavlath 2004). However, it might be possible that IL-4 activates different pathways in different cells to achieve cell fusion. Alternatively, IL-4 might trigger only the initial steps that lead to increased propensity for cell fusion. Completion of cell fusion might then be a consecutive step that occurs stochastically depending on the respective cell type.

\section{Materials and methods}

Cell culture and isolation of mesenchymal stem cells

mBM-MASCs were isolated from the bone marrow of 2-mo-old ICR mice (Prockop 1997) or from MLC1/3-LacZ transgenic mice crossed to a C57/BL6 background (Kelly et al. 1995) and separated from nonadherent hematopoietic cells by repetitive washing and medium changes. Homogeneous mBM-MASCs were obtained by clonal expansion and propagated continuously for $>3$ mo. Details will be described elsewhere (F. Belema-Bedada, A. Techmau, H. Ebelt, M. Schulze, and T. Braun, in prep.). Human mesenchymal stem cells were prepared from the femurs of anonymous donors (50-80 yr old) undergoing hip surgery, using essentially the same protocol as for mouse cells. Cells were cultured in DMEM supplemented with MSCGM-Single-Quots (GM-MSC-DMEM; Cambrex) (human cells) or in DMEM containing $10 \%(\mathrm{v} / \mathrm{v})$ FCS (mouse cells).

\section{Induction of MASC cell differentiation and coculture} with skeletal and heart muscle cells

To activate cell differentiation, MASCs were cocultured with Wnt11-expressing cells in DMEM supplemented with 3\% FCS $(\mathrm{v} / \mathrm{v})$ for 7 or $8 \mathrm{~d}$ with a medium change at day 4 . Wnt11-expressing cells were obtained by cloning the coding region of Wnt11 into the retroviral vector pMSCVneo (Clontech). The resulting plasmid was introduced together with amphotrophic packaging plasmids into the C2BAC packaging cell line (American Type Culture Collection) and selected for stable integration using $1.5 \mathrm{mg} / \mathrm{mL}$ G418 (Invitrogen). Packaging cells were treated with mitomycinC (Sigma) as described (Braun et al. 1992) before coculture with MASCs to prevent overgrowth. To activate heart-muscle-specific genes, mBM-MASC1 and mBMMASC2 were treated with $5 \mathrm{ng}$ FGF-2/mL alone or with $1 \mathrm{ng}$ of FGF-2 plus 0.6 ng BMP-2/mL in DMEM containing $3 \%$ FCS for $14-21 \mathrm{~d}$. 
Human and mouse MASCs were labeled either with DiI (Molecular Probes Inc.) or by infection with a GFP-expressing adenovirus and cocultered with $\mathrm{C} 2 \mathrm{C} 12$ cells or primary myoblasts isolated from the leg muscles of adult ICR-mice (Oustanina et al. 2004) Primary cardiomyocytes were obtained as described (Ebelt and Braun 2003). DiI treatment usually resulted in labeling of all cells, while $\sim 80 \%$ of MASCs became GFP-positive after adenoviral infection. Approximately $4 \times 10^{5}$ GFP-labeled MASCs were added to cultures of $\mathrm{C} 2 \mathrm{C} 12$ cells or primary myoblasts in six-well dishes that had reached $\sim 80 \%$ confluency. One day later, DMEM with $5 \%$ horse serum was added and the cells were allowed to differentiate for 5-6 d. To analyze the effects of IL-4, the same experimental setup was used with the only exception that IL-4 and antibodies against IL-4 and the IL-4 receptor were added at indicated concentrations (all supplied by R\&D Systems).

For filter experiments, polycarbonate filters (Nunc) with different pore sizes were used $(0.4,3.0$, and $8.0 \mu \mathrm{m})$. Labeled MASCs and unmarked $\mathrm{C} 2 \mathrm{C} 12$ cells were plated on opposite sides of filters and allowed to attach before differentiation medium was added. After 5-6 d, cells on the filters were stained with the MyHC-specific MF20antibody (Neuhaus et al. 2003).

\section{Immunostaining and FACS analysis}

For immunofluorescence, cells and sections were stained applying standard procedures (Oustanina et al. 2004). The following antibodies were used: MF20, anti-myogenin, anti-prolyl 4-hydroxylase (Dako), anti-Vimentin-antibody (Cymbus Biotechnology), and cTnI (Sigma). Secondary antibodies were coupled with Alexa 596 (red), Alexa 350 (blue), and Alexa 488 (green) and used according to the manufacturer's instructions (Molecular Probes). Nuclei were visualized using a $30 \mu \mathrm{M}$ DAPI solution (Molecular Probes).

MASCs were characterized at various time points by standard flow cytometry using PE-conjugated antibodies against Sca-1, c-Kit, CD34, CD45, SSEA-1, CD133/prominin, Ter 119 (GlycophorinA), Flk-1, CD13, and MHC1(H-2D d). Data collected from $>10,000$ cells were expressed as the percentage of positive cells per total gated cells. Raw data were analyzed using the CellQuest Pro software (BD Inc.).

\section{RNA isolation and RT-PCR}

Total RNA was isolated from tissues and cells using Trizol (Invitrogen). RT-PCR analyses were performed using $1 \mu \mathrm{g}$ of DNAse-treated RNA as described (Mennerich and Braun 2001). Depending on the gene of interest, between 25 and 35 PCR cycles were used with annealing temperatures ranging from $58^{\circ} \mathrm{C}$ to $67^{\circ} \mathrm{C}$. Detailed protocols and primer sequences are available from the authors on request. In all cases a housekeeping gene, GAPDH, was used as an internal control. PCR products were size-fractionated on $2 \%$ agarose gel electrophoresis, stained with ethidium bromide, and quantified using a gel documentation system. Identities of PCR products were corroborated by DNA sequence analysis or hybridization with specific probes.

\section{Generation and analysis of chimeric mice}

To generate chimeric mice, 10-20 MASCs were injected into blastocysts isolated from wild-type C57/BL6, IL-4 ${ }^{-1-}$, NFATc2 ${ }^{-1}$ ${ }_{-}, \mathrm{NFATc}^{-/-}$mutant, or NFATc2 ${ }^{-/-} \mathrm{c3}^{-/-}$mice as described previously (Braun et al. 1992; Braun and Arnold 1995). Chimeric embryos were cultivated for $1-3 \mathrm{~h}$ before transplantation into foster mothers. Embryos were dissected between E10.5 and
E14.5 and subjected to $\beta$-galactosidase staining and immunohistochemistry using the monoclonal anti-MyHC antibodies MF20 and MY32. $\beta$-Galactosidase staining of whole-mount preparations, sectioning, and immunohistochemistry were performed as described (Kruger and Braun 2002). After $\beta$-galactosidase staining, the presence of MASC-derived cells in chimeric embryos was monitored by PCR-based detection of the transgenic LacZ marker (Mennerich and Braun 2001). The gene for intestinal fatty acid-binding protein was amplified as an internal control as described (Stratman et al. 2003). The generation of IL-4 $^{-/-}$(Kuhn et al. 1991), NFATc2 ${ }^{-/-}$(Schuh et al. 1998), and $\mathrm{NFATc}^{-/-}$mutant mice (Rengarajan et al. 2002) has been described before. NFAT mutant mice were kindly supplied by Professor Edgar Serfling (University of Würzburg, Würzburg, Germany). IL-4 ${ }^{-/-}$mice were obtained from Jackson Laboratories. NFATc2 $2^{-/-}$mutant or NFATc2 $2^{-/-} \mathrm{c}^{-/-}$blastocysts were obtained by intercrossing NFATc2 $2^{-/}$mice or by crossing NFATc2 $2^{-/-} \mathrm{c}^{+/-}$with NFATc2 $2^{-/-} \mathrm{c}^{+/-}$or NFATc2 $2^{+/-} \mathrm{c}^{-/-}$mice. Genotyping of embryos was performed by PCR with DNA isolated from yolk sacs using standard procedures. The following primers were used for genotyping: NFATc2: CAAGCCTCAT GTACAAAGTATCCACTTC and AGCGTTGGCTACCCGT GATATTGC (mutant); CAAGCCTCATGTACAAAGTATC CACTTC and CGAGCTGCCCATGGTGGAGAGAC /wild type). NFATc3: CAGCTGTGAGCTACCTTATGGAAGC and AGCGTTGGCTACCGTGATATTGC (mutant); CAGCTGT GAGCTACCTTATGGAAGC and GCTCTAAAGATGGCTC CGTGC (wild type).

\section{Acknowledgments}

We thank Katja Zabel and Katja Kolditz for expert technical assistance. We are indebted to Edgar Serfling and Alois Palmetshofer (University of Würzburg) for supplying NFATc2 and to Laurie Glimcher (Harvard Medical School, Boston, MA) for providing NFATc3 mutant mice. We further thank Sawa Kostin for his expert help with microscopic imaging and Henning Ebelt for assistance with FACS analysis. This work was supported by the Max-Planck-Society, the DFG (priority program "stem cells"), the BMBF, and the Wilhelm-Roux-Program for Research of the Martin-Luther-University. The authors declare that they have no conflicting commercial interests related to this work.

\section{References}

Badorff, C., Brandes, R.P., Popp, R., Rupp, S., Urbich, C., Aicher, A., Fleming, I., Busse, R., Zeiher, A.M., and Dimmeler, S. 2003. Transdifferentiation of blood-derived human adult endothelial progenitor cells into functionally active cardiomyocytes. Circulation 107: 1024-1032.

Balsam, L.B., Wagers, A.J., Christensen, J.L., Kofidis, T., Weissman, I.L., and Robbins, R.C. 2004. Haematopoietic stem cells adopt mature haematopoietic fates in ischaemic myocardium. Nature 428: 668-673.

Bittner, R.E., Schofer, C., Weipoltshammer, K., Ivanova, S., Streubel, B., Hauser, E., Freilinger, M., Hoger, H., ElbeBurger, A., and Wachtler, F. 1999. Recruitment of bone-marrow-derived cells by skeletal and cardiac muscle in adult dystrophic mdx mice. Anat. Embryol. (Berl) 199: 391-396.

Blau, H.M., Pavlath, G.K., Hardeman, E.C., Chiu, C.P., Silberstein, L., Webster, S.G., Miller, S.C., and Webster, C. 1985. Plasticity of the differentiated state. Science 230: 758-766.

Braun, T. and Arnold, H.H. 1995. Inactivation of Myf-6 and Myf- 5 genes in mice leads to alterations in skeletal muscle development. EMBO J. 14: 1176-1186. 
Braun, T., Rudnicki, M.A., Arnold, H.H., and Jaenisch, R. 1992. Targeted inactivation of the muscle regulatory gene Myf-5 results in abnormal rib development and perinatal death. Cell 71: 369-382.

Camargo, F.D., Green, R., Capetenaki, Y., Jackson, K.A., and Goodell, M.A. 2003. Single hematopoietic stem cells generate skeletal muscle through myeloid intermediates. Nat. Med. 9: 1520-1527.

Cerny, J. and Quesenberry, P.J. 2004. Chromatin remodeling and stem cell theory of relativity. J. Cell Physiol. 201: 1-16.

Chatila, T.A. 2004. Interleukin-4 receptor signaling pathways in asthma pathogenesis. Trends Mol. Med. 10: 493-499.

De Angelis, L., Berghella, L., Coletta, M., Lattanzi, L., Zanchi, M., Cusella-De Angelis, M.G., Ponzetto, C., and Cossu, G. 1999. Skeletal myogenic progenitors originating from embryonic dorsal aorta coexpress endothelial and myogenic markers and contribute to postnatal muscle growth and regeneration. J. Cell Biol. 147: 869-878.

Dworak, H.A. and Sink, H. 2002. Myoblast fusion in Drosophila. Bioessays 24: 591-601.

Ebelt, H. and Braun, T. 2003. Optimized, highly efficient transfer of foreign genes into newborn mouse hearts in vivo. Biochem. Biophys. Res. Commun. 310: 1111-1116.

Eisenberg, C.A. and Eisenberg, L.M. 1999. WNT11 promotes cardiac tissue formation of early mesoderm. Dev. Dyn. 216: 45-58.

Ferrari, G. and Mavilio, F. 2002. Myogenic stem cells from the bone marrow: A therapeutic alternative for muscular dystrophy? Neuromuscul. Disord. 12 (Suppl. 1): S7-S10.

Ferrari, G., Cusella-De Angelis, G., Coletta, M., Paolucci, E., Stornaiuolo, A., Cossu, G., and Mavilio, F. 1998. Muscle regeneration by bone marrow-derived myogenic progenitors. Science 279: 1528-1530.

Fukuhara, S., Tomita, S., Nakatani, T., Yutani, C., and Kitamura, S. 2005. Endogenous bone-marrow-derived stem cells contribute only a small proportion of regenerated myocardium in the acute infarction model. J. Heart Lung Transplant 24: 67-72.

Gussoni, E., Soneoka, Y., Strickland, C.D., Buzney, E.A., Khan, M.K., Flint, A.F., Kunkel, L.M., and Mulligan, R.C. 1999. Dystrophin expression in the $\mathrm{mdx}$ mouse restored by stem cell transplantation. Nature 401: 390-394.

Horsley, V. and Pavlath, G.K. 2004. Forming a multinucleated cell: Molecules that regulate myoblast fusion. Cells Tissues Organs 176: 67-78.

Horsley, V., Friday, B.B., Matteson, S., Kegley, K.M., Gephart, J., and Pavlath, G.K. 2001. Regulation of the growth of multinucleated muscle cells by an NFATC2-dependent pathway. J. Cell Biol. 153: 329-338.

Horsley, V., Jansen, K.M., Mills, S.T., and Pavlath, G.K. 2003. IL-4 acts as a myoblast recruitment factor during mammalian muscle growth. Cell 113: 483-494.

Jackson, K.A., Mi, T., and Goodell, M.A. 1999. Hematopoietic potential of stem cells isolated from murine skeletal muscle. Proc. Nat1. Acad. Sci. 96: 14482-14486.

Jiang, Y., Jahagirdar, B.N., Reinhardt, R.L., Schwartz, R.E., Keene, C.D., Ortiz-Gonzalez, X.R., Reyes, M., Lenvik, T., Lund, T., Blackstad, M., et al. 2002. Pluripotency of mesenchymal stem cells derived from adult marrow. Nature 418: 41-49.

Kegley, K.M., Gephart, J., Warren, G.L., and Pavlath, G.K. 2001. Altered primary myogenesis in $\mathrm{NFATC}^{-/-}$mice leads to decreased muscle size in the adult. Dev. Biol. 232: 115-126.

Kelly, R., Alonso, S., Tajbakhsh, S., Cossu, G., and Buckingham, M. 1995. Myosin light chain 3F regulatory sequences confer regionalized cardiac and skeletal muscle expression in transgenic mice. J. Cell Biol. 129: 383-396.

Kruger, M. and Braun, T. 2002. The neuronal basic helix-loophelix transcription factor NSCL-1 is dispensable for normal neuronal development. Mol. Cell. Biol. 22: 792-800.

Kuhn, R., Rajewsky, K., and Muller, W. 1991. Generation and analysis of interleukin-4 deficient mice. Science 254: 707710.

LaBarge, M.A. and Blau, H.M. 2002. Biological progression from adult bone marrow to mononucleate muscle stem cell to multinucleate muscle fiber in response to injury. Cell 111: 589-601.

Lickert, H., Takeuchi, J.K., Von Both, I., Walls, J.R., McAuliffe, F., Adamson, S.L., Henkelman, R.M., Wrana, J.L., Rossant, J., and Bruneau, B.G. 2004. Baf60c is essential for function of BAF chromatin remodelling complexes in heart development. Nature 432: 107-112.

Mathur, A. and Martin, J.F. 2004. Stem cells and repair of the heart. Lancet 364: 183-192.

Mennerich, D. and Braun, T. 2001. Activation of myogenesis by the homeobox gene Lbx1 requires cell proliferation. EMBO $J$. 20: 7174-7183.

Murry, C.E., Soonpaa, M.H., Reinecke, H., Nakajima, H., Nakajima, H.O., Rubart, M., Pasumarthi, K.B., Virag, J.I., Bartelmez, S.H., Poppa, V., et al. 2004. Haematopoietic stem cells do not transdifferentiate into cardiac myocytes in myocardial infarcts. Nature 428: 664-668.

Neuhaus, P. and Braun, T. 2002. Transcription factors in skeletal myogenesis of vertebrates. Results Probl. Cell Differ. 38: 109-126.

Neuhaus, P., Oustanina, S., Loch, T., Kruger, M., Bober, E., Dono, R., Zeller, R., and Braun, T. 2003. Reduced mobility of fibroblast growth factor (FGF)-deficient myoblasts might contribute to dystrophic changes in the musculature of FGF2/FGF6/mdx triple-mutant mice. Mol. Cell. Biol. 23: 6037-6048.

Olson, E.N. and Schneider, M.D. 2003. Sizing up the heart: Development redux in disease. Genes \& Dev. 17: 1937-1956.

Orlic, D., Kajstura, J., Chimenti, S., Jakoniuk, I., Anderson, S.M., Li, B., Pickel, J., McKay, R., Nadal-Ginard, B., Bodine, D.M., et al. 2001. Bone marrow cells regenerate infarcted myocardium. Nature 410: 701-705.

Oustanina, S., Hause, G., and Braun, T. 2004. Pax7 directs postnatal renewal and propagation of myogenic satellite cells but not their specification. EMBO J. 23: 3430-3439.

Pandur, P., Lasche, M., Eisenberg, L.M., and Kuhl, M. 2002. Wnt-11 activation of a non-canonical Wnt signalling pathway is required for cardiogenesis. Nature 418: 636-641.

Pavlath, G.K. and Horsley, V. 2003. Cell fusion in skeletal muscle-Central role of NFATC2 in regulating muscle cell size. Cell Cycle 2: 420-423.

Polesskaya, A., Seale, P., and Rudnicki, M.A. 2003. Wnt signaling induces the myogenic specification of resident CD45+ adult stem cells during muscle regeneration. Cell 113: $841-$ 852.

Prockop, D.J. 1997. Marrow stromal cells as stem cells for nonhematopoietic tissues. Science 276: 71-74.

Rengarajan, J., Tang, B., and Glimcher, L.H. 2002. NFATc2 and NFATc3 regulate $\mathrm{T}(\mathrm{H}) 2$ differentiation and modulate TCRresponsiveness of naive $\mathrm{T}(\mathrm{H})$ cells. Nat. Immunol. 3: 48-54.

Schuh, K., Kneitz, B., Heyer, J., Bommhardt, U., Jankevics, E., Berberich-Siebelt, F., Pfeffer, K., Muller-Hermelink, H.K., Schimpl, A., and Serfling, E. 1998. Retarded thymic involution and massive germinal center formation in NF-ATp-deficient mice. Eur. J. Immunol. 28: 2456-2466. 
Schulze et al.

Seale, P., Sabourin, L.A., Girgis-Gabardo, A., Mansouri, A., Gruss, P., and Rudnicki, M.A. 2000. Pax7 is required for the specification of myogenic satellite cells. Cell 102: 777-786.

Solloway, M.J. and Harvey, R.P. 2003. Molecular pathways in myocardial development: A stem cell perspective. Cardiovasc. Res. 58: 264-277.

Stratman, J.L., Barnes, W.M., and Simon, T.C. 2003. Universal PCR genotyping assay that achieves single copy sensitivity with any primer pair. Transgenic Res. 12: 521-522.

Taylor, M.V. 2002. Muscle differentiation: How two cells become one. Curr. Biol. 12: R224-R228.

Terada, N., Hamazaki, T., Oka, M., Hoki, M., Mastalerz, D.M., Nakano, Y., Meyer, E.M., Morel, L., Petersen, B.E., and Scott, E.W. 2002. Bone marrow cells adopt the phenotype of other cells by spontaneous cell fusion. Nature 416: 542-545.

Tzahor, E. and Lassar, A.B. 2001. Wnt signals from the neural tube block ectopic cardiogenesis. Genes \& Dev. 15: 255-260.

Wagers, A.J., Sherwood, R.I., Christensen, J.L., and Weissman, I.L. 2002. Little evidence for developmental plasticity of adult hematopoietic stem cells. Science 297: 2256-2259.

Ying, Q.L., Nichols, J., Evans, E.P., and Smith, A.G. 2002. Changing potency by spontaneous fusion. Nature 416: $545-$ 548.

Zaffran, S. and Frasch, M. 2002. Early signals in cardiac development. Circ. Res. 91: 457-469. 


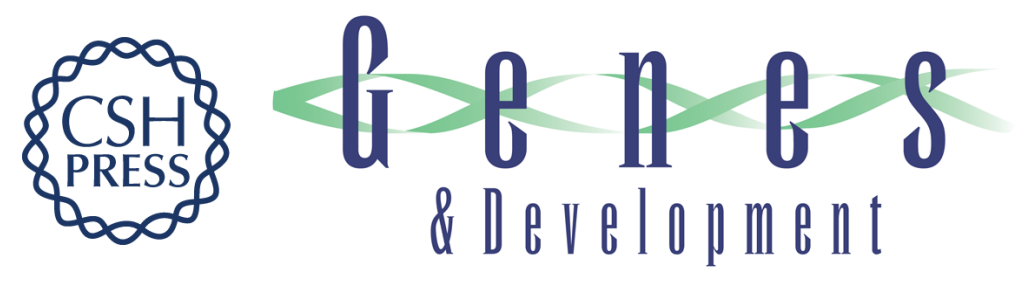

\section{Mesenchymal stem cells are recruited to striated muscle by NFAT/IL-4-mediated cell fusion}

Manja Schulze, Fikru Belema-Bedada, Antje Technau, et al.

Genes Dev. 2005, 19:

Access the most recent version at doi:10.1101/gad.339305

Supplemental http://genesdev.cshlp.org/content/suppl/2005/07/29/19.15.1787.DC1
Material

References This article cites 50 articles, 16 of which can be accessed free at: http://genesdev.cshlp.org/content/19/15/1787.full.html\#ref-list-1

License

Email Alerting

Receive free email alerts when new articles cite this article - sign up in the box at the top Service right corner of the article or click here.

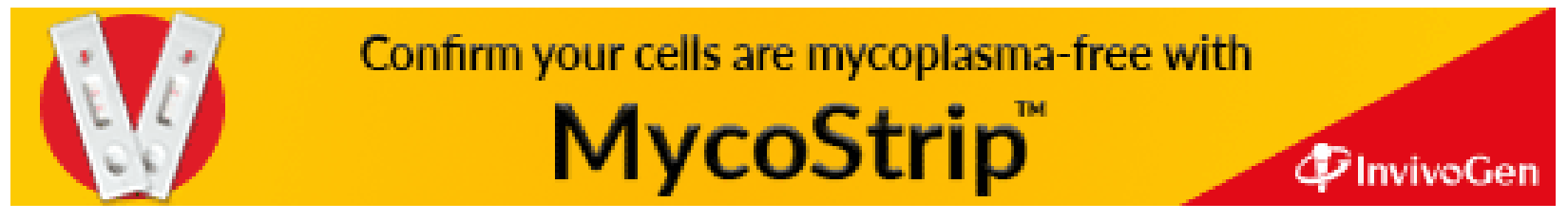

